\title{
The role of adverse childhood experiences in risky behaviors, health care utilization, and generalized self-efficacy in the general adult Polish population
}

\author{
Dominika Berent ${ }^{1}$, Marcin Wojnar ${ }^{2,3}$
}

${ }^{1}$ Masovian Regional Psychiatric Hospital Drewnica, Ząbki, Poland
${ }^{2}$ Medical University of Warsaw, Warsaw, Poland
${ }^{3}$ University of Michigan, Ann Arbor, MI, USA

Submitted: 3 April 2019

Accepted: 21 December 2019

Arch Med Sci

DOI: https://doi.org/10.5114/aoms.2020.96084

Copyright $\odot 2020$ Termedia \& Banach

\section{Abstract}

Introduction: The present study evaluated whether adverse childhood experiences (ACEs) are significantly and independently associated with six key outcomes in the Polish general population: (1) lifetime suicide attempt, (2) self-mutilation, (3) potential problem drinking, (4) use of street drugs, (5) visiting a psychologist/psychotherapist, and (6) visiting a psychiatrist. We also investigated whether ACEs explain a significant proportion of variability in generalized self-efficacy.

Material and methods: Six hundred and fifty-nine individuals completed the ACE Study questionnaire (physical, verbal, and sexual abuse; neglect; select family dysfunctions) and three additional questions [ACE (13) questionnaire]: witnessing (1) a family member's suicide attempt or (2) death due to any cause except completed suicide, and (3) a stranger's death due to any cause (e.g., traffic accident). Generalized self-efficacy was assessed with the Generalized Self-Efficacy Scale.

Results: The likelihood of lifetime use of street drugs, potential problem drinking, and visiting a psychologist/psychotherapist and psychiatrist increased as ACE and ACE (13) score increased. As compared to scores of < 4, ACE (13) scores of $\geq 4$ were associated with a 10.8-fold increased likelihood of self-mutilation, a 3.26-fold increased likelihood of potential problem drinking, a 5.72-fold increased likelihood of visiting a psychologist/psychotherapist, and a 6.71-fold increased likelihood of visiting a psychiatrist. ACE (13) score explained $1.2 \%$ of the variability in generalized self-efficacy. Conclusions: The present study identified a strong association between childhood adversity and increased likelihood of lifetime self-mutilation, potential problem drinking, visiting a psychologist/psychotherapist, and visiting a psychiatrist. Generalized self-efficacy may be an important target for secondary intervention following childhood adversity.

Key words: general population, adulthood, health harming behavior, lifethreatening behavior, childhood adversity, generalized self-efficacy.

\section{Introduction}

Adverse childhood experiences (ACEs) have been reported to increase the risk of developing health harming behaviors and premature death in adulthood. The ACE Study started in 1992 and examined thousands of patients undergoing comprehensive medical evaluation for any cause in Kaiser Permanente's San Diego Health Appraisal Clinic, a primary care

\author{
Corresponding author: \\ Dominika Berent \\ Masovian Regional Psychiatric \\ Hospital Drewnica \\ Ząbki, Poland \\ E-mail: \\ dominikaberent@poczta.fm
}


clinic [1, 2]. The ACE Study questionnaire comprised questions about the following ACE categories that took place before the age of 18: physical, verbal, and sexual abuse, neglect, loss of one or both parents for any reason, exposure to domestic violence between family members, and growing up in a household with mental illness, alcohol abuse, drug abuse, or incarceration. In that study, ACEs were significantly related to health-risk behaviors later in life, including smoking, illicit substance use, suicide attempt, excessive drinking, or unsafe sexual practices. Further, individuals reporting $\geq 4$ ACEs had a 1.8 times higher risk of premature death than individuals reporting no ACEs [2]. A British national survey, which implemented the ACE Study questionnaire to assess self-reporting of childhood victimization in a general population, found that the odds ratio for mortality before age 70 years was strongly linked to ACEs. Indeed, the increased risk of mortality before age 70 reached 1.97 in individuals who reported $\geq$ 4 ACE categories as compared to individuals who reported no ACEs. The somatic disorders that were found to be associated with a higher rate of ACES included cancer, diabetes, and stroke [3].

Adverse childhood experiences have been found to have profound effects on mental health in adulthood. They were more frequently reported by patients with uni- and bipolar depression, a lifetime suicide attempt, and alcohol dependence [4-7]. Adverse childhood experiences were found to trigger adverse adaptation after victimization in childhood and young adulthood and to impair generalized self-efficacy, which is an intrinsic psychological source of the ability to cope with unexpected life-demanding stress later in life [8]. In a study on patients with alcohol dependence, ACEs were shown to reduce generalized self-efficacy, and explained $3.2 \%$ of the variance in self-efficacy [7].

To our knowledge, this is the first study to test whether the 13 ACE categories are significantly and independently associated with six key outcomes in the Polish general population: (1) lifetime suicide attempt, (2) self-mutilation, (3) potential problem drinking, (4) use of street drugs, (5) visiting a psychologist or psychotherapist, and (6) visiting a psychiatrist. The second aim was to investigate whether ACEs explain a significant proportion of variability in generalized self-efficacy.

\section{Material and methods}

\section{Study sample}

Volunteers from the general population were recruited to the study from the local communities on invitation to respond an anonymous questionnaire. Potential participants were informed that they had the right to withdraw their consent at any time during the study without giving any rea- son. Study participants were ensured confidentiality of the provided data. Of the 705 individuals who initially qualified for the study, 46 were excluded from the analysis due to incomplete data or consent withdrawal (i.e., finding the questionnaire too intimate or time-consuming). The final study sample consisted of 659 healthy volunteers (564 female), aged $43.38 \pm 8.59$ years (mean \pm SD).

\section{Measures \\ Final outcomes, social and demographic variables}

Sociodemographic characteristics and five of the six outcomes variables (i.e., lifetime suicide attempt, self-mutilation, street drug use, visit to a psychologist/psychotherapist, visit to a psychiatrist) were collected using a structured self-report questionnaire designed for the study. Participants were questioned about five of the six final outcomes using the following questions, written in the Polish language:

- lifetime suicide attempt: "Have you ever tried to commit suicide during your lifetime?" (Yes/No question),

- lifetime self-mutilation: "Have you ever self-mutilated during your lifetime (cut your skin, scratched your skin heavily, burned your skin)?" (Yes/No question),

- lifetime street drug use "How old were you when you first used a street drug?" (Possible answers: giving the age [considered as self-confirmed lifetime street drug use] or choosing the statement "I have never used street drugs"),

- lifetime visiting a psychologist/psychotherapist: "Have you ever visited a psychologist/psychotherapist seeking help during your lifetime?" (Yes/No question),

- lifetime visiting a psychiatrist: "Have you ever visited a psychiatrist seeking help during your lifetime?" (Yes/No question).

The last outcome measure (i.e., potential problem drinking) was assessed using the Polish version of the CAGE questionnaire, an open access screening tool that contains four Yes/No questions. Obtaining $\geq 1$ point of the 4 possible suggests a need for further diagnostic evaluation, but is not sufficient for establishing a diagnosis of problem drinking. A meta-analysis of 22 English language studies reported the median internal reliability measured by a Cronbach $\alpha$ of 0.74 [9]. However, the Polish version of the CAGE questionnaire has not yet been validated. Problem drinking is defined as consumption of alcohol to the extent that it adversely influences a person's mental or physical health, social life, or career. Problem drinking can refer to a moderate drinker, heavy drinker, or binge drinker. The most severe level 
of problem drinking implies an alcohol use disorder (i.e., alcohol abuse and alcohol dependence).

\section{Adverse childhood experiences}

Childhood and adolescence victimization was identified with Yes/No questions about 13 categories of ACEs occurring during the first 18 years of life. The first 10 questions used by Kaiser Permanente and the Centers for Disease Control and Prevention (the ACE Study questionnaire) inquire about chronic exposure to abuse (physical, verbal, and sexual abuse; neglect) and family dysfunction (i.e., the loss of one or both parents for any reason; exposure to domestic violence between family members; and growing up in a household with mental illness, alcohol abuse, drug abuse, or incarceration) [1]. We added three more questions to the structured self-report questionnaire designed for this study to evaluate events that also took place under the age of 18, and are considered to be acute stressors, including: witnessing a family member's suicide attempt; witnessing a family member's death due to any cause (except for completed suicide); and witnessing a stranger's death due to any cause (e.g., traffic accident). For the purpose of our study, the list of the standard 10 ACE Study questions together with our three additional ACE acute stressors questions is referred to as the 'ACE (13)' questionnaire. The statistical analysis assessed self-reported childhood victimization with both the ACE Study questionnaire and ACE (13) questionnaire, which allows our results to be comparable with studies that utilize the ACE Study questionnaire.

The original version of the ACE Study questionnaire (10 questions) in English was translated into Polish (with Prof. V.J. Felitti's permission), and then back-translated to check the accuracy of the Polish version. The Polish version of the ACE Study questionnaire was initially applied to 50 individuals from the local community (i.e., medical doctors, academic teachers, hospital staff and their family members) and provided feedback on clarity of wording. The internal consistency, assessed on the basis of Cronbach's $\alpha$, in the present study group was 0.77 for the Polish version of the ACE Study questionnaire, and was 0.72 for the ACE (13) questionnaire.

\section{Generalized self-efficacy}

Generalized self-efficacy was measured with the Polish validated version of the 10-item Generalized Self-Efficacy Scale (GSES) developed by Schwarzer, Jerusalem, and Juczyński. Generalized self-efficacy refers to social coping skills related to belief in one's own resourcefulness to cope with a variety of unforeseen situations in everyday life, i.e., facing a demanding problem or a confrontation with an oppositional individual [10]. The internal reliabil- ity of the Polish version of the GSES as measured by Cronbach's a is 0.85 [10]. Responses are made on a 4-point scale for a generalized sense of self-efficacy [10].

\section{Ethics}

Study participants gave written informed consent to participate in the study. The study was approved by the Local Bioethics Committees: Nos. RNN/467/13/KB and KB/843/13/P. The study was carried out in accordance with the ethical standards established in the 1964 Declaration of Helsinki and its later amendments.

\section{Statistical analysis}

Calculations were performed using SPSS Statistics, version 25 (IBM Corp.). Normality of data distribution was evaluated with the Shapiro-Wilk test.

Between-group comparisons were made using the Mann-Whitney $U$ test for independent samples (i.e., differences between ranks). Contingency tables were compared using the $\chi^{2}$ test when the expected numbers exceeded 5 , or using the Fisher exact test when the expected numbers were below 5 . Spearman's rank correlation coefficients were estimated to evaluate the correlation between age and generalized self-efficacy (GSES), and between the number of ACE categories (ACE (13) questionnaire) and generalized self-efficacy (GSES). Bonferroni correction for multiple testing was applied.

Changes in the odds ratio (OR) of our various outcomes (i.e., lifetime suicide attempt, self-mutilation, potential problem drinking, using street drugs, visiting a psychologist/psychotherapist, visiting a psychiatrist) with an increased history of ACE categories was assessed using logistic regression. Adverse childhood experience categories were self-reported using: (1) the ACE Study questionnaire (0 to 10 possible ACE categories), (2) the ACE (13) questionnaire (0 to 13 possible ACE categories), and (3) an ACE (13) cumulative score of $\geq 4$. Generalized Self-Efficacy Scale and sociodemographic variables were controlled for in analyses.

Linear regression was applied to test the relationship between generalized self-efficacy (GSES) and various independent variables.

The level of statistical significance was set at $p<0.05$.

\section{Results}

Baseline participant characteristics, selfreported adverse childhood experience categories, and lifetime outcome measures

Baseline characteristics of the study participants are presented in Table I. The prevalence of each ACE category in the whole study sample, as 
Table I. Baseline characteristics of the study group $(N=659)$

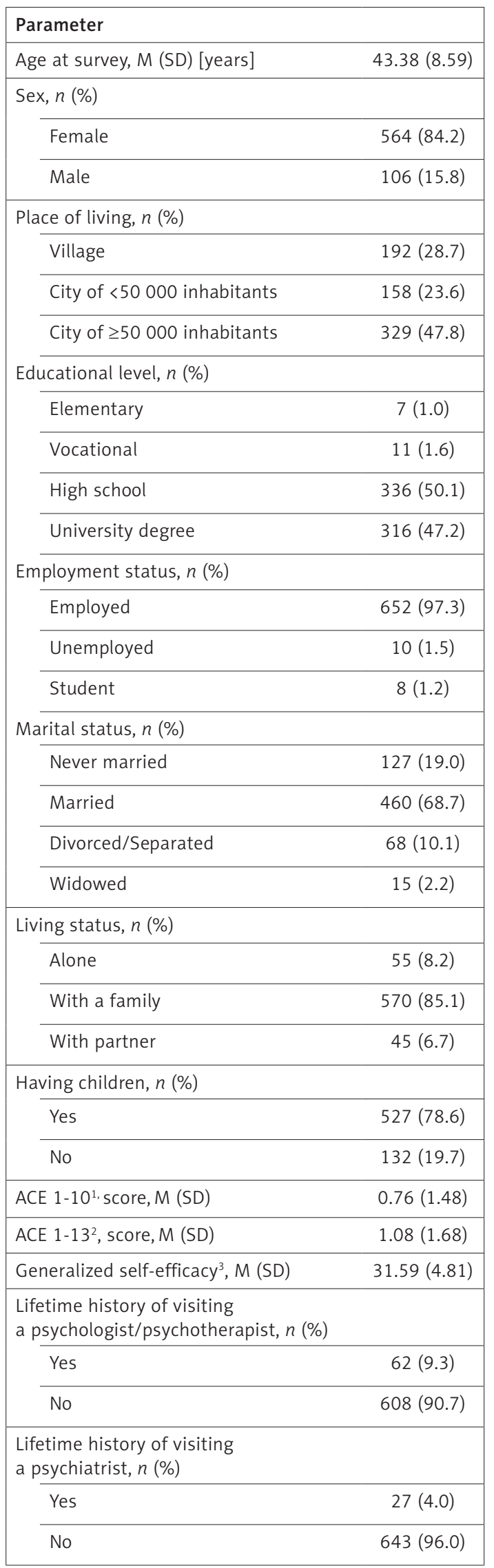

\begin{tabular}{|c|c|}
\hline \multicolumn{2}{|l|}{ Parameter } \\
\hline \multicolumn{2}{|c|}{ Lifetime history of suicide attempt, $n$ (\%) } \\
\hline Yes & $7(1.0)$ \\
\hline No & 663 (99.0) \\
\hline \multicolumn{2}{|c|}{ Lifetime history of self-mutilation, $n(\%)$} \\
\hline Yes & $6(0.9)$ \\
\hline No & $664(99.1)$ \\
\hline \multicolumn{2}{|c|}{ Potential problem drinking ${ }^{4}, n(\%)$} \\
\hline Yes & $78(11.6)$ \\
\hline No & $592(88.4)$ \\
\hline \multicolumn{2}{|c|}{ Lifetime history of street drug use, $n(\%)$} \\
\hline Yes & $18(2.7)$ \\
\hline no & $652(97.3)$ \\
\hline \multicolumn{2}{|c|}{$\begin{array}{l}\text { ACE cumulative score on the ACE (13) } \\
\text { questionnaire }\end{array}$} \\
\hline$<4$ of 13 & $605(91.8)$ \\
\hline 4 and more of 13 & $54(8.2)$ \\
\hline
\end{tabular}

$M$ - mean, SD - standard deviation. ${ }^{1}$ Number of ACEs assessed with the ACE Study questionnaire. ${ }^{2}$ Number of ACEs assessed with the ACE (13) questionnaire. ${ }^{3}$ Assessed with Generalized Self-Efficacy Scale. ${ }^{4}$ Assessed with the CAGE questionnaire, score of $\geq 1$ point marked as 'Yes'.

well as in males and females separately, is shown in Figure $1 \mathrm{~A}$ and $\mathrm{B}$, respectively. Of the 659 study participants, almost half (48.1\%) reported at least one ACE category on the ACE (13) questionnaire. A significantly higher proportion of males reported exposure to none of the ACE (13) categories (i.e., $1-13)$ than females ( $57.4 \%$ vs. $49.3 \%, p=0.002$ ) (Figure 1 B). Indeed, males were less likely to report physical abuse (ACE 2), problem drinking/ alcoholic/street drug use of a household member (ACE 8), and witnessing a family member's death of any cause, except for completed suicide (ACE 12) than females $(p=0.04, p=0.002, p=0.011$, respectively) (Figure $1 \mathrm{~B}$ ).

The prevalence of ever visiting a psychologist/ psychotherapist or a psychiatrist among individuals with a positive lifetime history of suicide attempt, self-mutilation, potential problem drinking and street drug use is presented in Table II. Of the 659 study participants, 62 (9.3\%) reported visiting a psychologist/psychotherapist at least once during his/her lifetime and 27 (4.0\%) reporting visiting a psychiatrist (Table I). Twenty-two (36.1\%) individuals reported visiting both a psychologist/ psychotherapist and a psychiatrist during his/her lifetime. None of the individuals from our study group reported experiencing $\geq 3$ of the four out- 
A

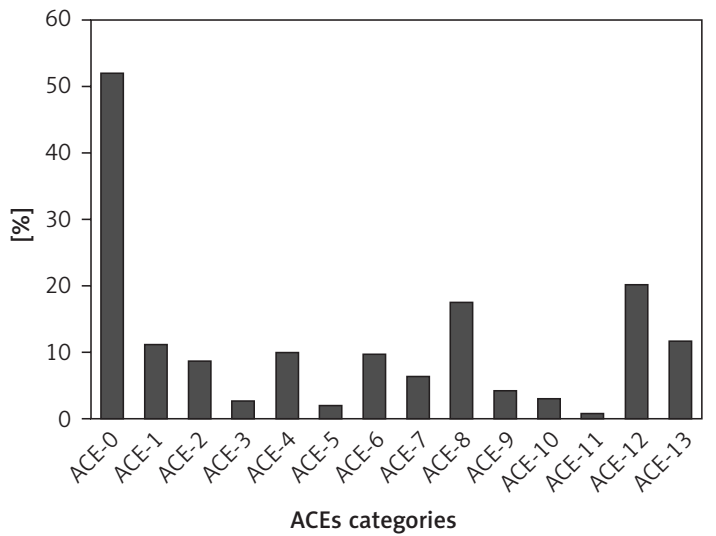

B

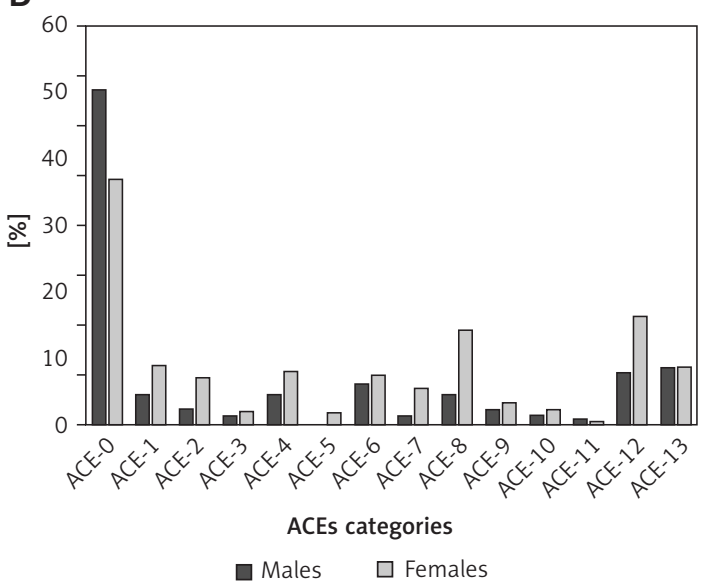

ACEO - no ACE reported, ACE1 - psychological abuse, ACE2 - physical abuse, ACE3 - sexual abuse, ACE4 - emotional neglect, ACE5 physical neglect, ACE6 - contact loss with one or both parent due to separation, divorce, or another reason, ACE7 - witnessing of physical abuse towards mother or stepmother, ACE8 - problem drinking/alcoholic/street drug use of household member, ACE9 - mental illness or suicide attempt of household member, ACE10 - incarceration of household member, ACE11 - witnessed family member's suicide attempt, ACE12 - witnessed family member's death of any cause, ACE13 - witnessed stranger's death of any cause (e.g., traffic accident)

Figure 1. A. The prevalence of self-reported adverse childhood experiences (ACEs) categories in the whole study group $(N=659)$. B. The prevalence of each self-reported ACE category in males $(n=106)$ and females $(n=564)$ of the study group

Table II. Prevalence of ever visiting a psychotherapist or psychiatrist among study group individuals $(N=659)$, by individual outcomes (i.e., lifetime history of suicide attempt, self-mutilation, potential problem drinking and street drug use)

\begin{tabular}{|c|c|c|c|c|}
\hline \multirow[t]{2}{*}{ Parameter } & \multicolumn{2}{|c|}{ Lifetime history of visiting a psychotherapist } & \multicolumn{2}{|c|}{ Lifetime history of visiting a psychiatrist } \\
\hline & $\begin{array}{c}\text { No } \\
n(\%)\end{array}$ & $\begin{array}{c}\text { Yes } \\
n(\%)\end{array}$ & $\begin{array}{c}\text { No } \\
n(\%)\end{array}$ & $\begin{array}{c}\text { Yes } \\
n(\%)\end{array}$ \\
\hline \multicolumn{5}{|c|}{ Suicide attempt } \\
\hline No & $594(91.1)$ & $58(8.9)$ & 625 (95.9) & $27(4.1)$ \\
\hline Yes & $4(57.1)$ & $3(42.9)$ & $7(100.0)$ & $0(0)$ \\
\hline \multicolumn{5}{|c|}{ Self-mutilation } \\
\hline No & $593(90.8)$ & $60(9.2)$ & $626(95.9)$ & $27(4.1)$ \\
\hline Yes & $5(83.3)$ & $1(16.7)$ & $6(100.0)$ & $0(0)$ \\
\hline \multicolumn{5}{|c|}{ Potential problem drinking ${ }^{1}$} \\
\hline No & $540(92.9)$ & $41(7.1)$ & $560(96.4)$ & $21(3.6)$ \\
\hline Yes & $58(74.4)$ & $20(25.6)$ & $72(92.3)$ & $6(7.7)$ \\
\hline \multicolumn{5}{|c|}{ Street drug use } \\
\hline No & $-583(91.0)$ & $58(9.0)$ & $614(95.8)$ & $27(4.2)$ \\
\hline Yes & $15(83.3)$ & $3(16.7)$ & $18(100.0)$ & $0(0)$ \\
\hline
\end{tabular}

${ }^{1}$ Assessed with CAGE questionnaire, score of $\geq 1$ point marked as 'Yes'.

comes measures (i.e., lifetime suicide attempt, self-mutilation, problem drinking, street drug use). Of the 563 individuals who reported experiencing none of the four outcomes, 21 individuals reported visiting a psychiatrist (3.7\%) and 36 (6.4\%) reported visiting a psychologist/psychotherapist during his/her lifetime. Of the 83 individuals who reported experiencing one of the four outcomes, $6(7.2 \%)$ reported visiting a psychiatrist and 23 (27.7\%) reported visiting a psychologist/psychotherapist during his/her lifetime. Of the 13 individuals who reported experiencing two of the four outcomes, none of these individuals reported visiting a psychiatrist $(0.0 \%)$ and only 2 (15.4\%) reported visiting a psychologist/psychotherapist during his/her lifetime (data not shown). 
Table III.

A. Comparison of individuals with $(n=7)$ and without $(n=652)$ lifetime history of a suicide attempt

\begin{tabular}{|c|c|c|c|}
\hline \multirow[t]{2}{*}{ Parameter } & \multicolumn{2}{|c|}{ Suicide attempt } & \multirow[t]{2}{*}{$P$} \\
\hline & No $(n=652)$ & Yes $(n=7)$ & \\
\hline Age at survey, M (SD) [years] & $43.34(8.61)$ & $46.71(6.10)$ & $0.297^{1}$ \\
\hline \multicolumn{4}{|l|}{ Sex, $n(\%)$} \\
\hline Female & $557(98.8)$ & $7(1.2)$ & \multirow[t]{2}{*}{$0.601^{3}$} \\
\hline Male & 95 (100.0) & $0(0.0)$ & \\
\hline \multicolumn{4}{|l|}{ Place of living, $n(\%)$} \\
\hline Village & $189(100.0)$ & $0(0)$ & \multirow[t]{3}{*}{$0.105^{3}$} \\
\hline City of $<50,000$ inhabitants & $154(99.3)$ & $1(0.7)$ & \\
\hline City of $\geq 50,000$ inhabitants & $309(98.1)$ & $6(1.9)$ & \\
\hline \multicolumn{4}{|l|}{ Educational level, $n$ (\%) } \\
\hline Elementary & $7(100.0)$ & $0(0)$ & \multirow[t]{4}{*}{$0.769^{3}$} \\
\hline Vocational & 11 (100.) & $0(0)$ & \\
\hline Secondary & $325(99.1)$ & $3(0.9)$ & \\
\hline University degree & $309(98.7)$ & $4(1.3)$ & \\
\hline \multicolumn{4}{|l|}{ Occupational status, $n$ (\%) } \\
\hline Employed & $636(98.9)$ & $7(1.1)$ & \multirow[t]{3}{*}{$>0.999^{3}$} \\
\hline Unemployed & $8(100.0)$ & $0(0.0)$ & \\
\hline Student & $8(100.0)$ & $0(0.0)$ & \\
\hline \multicolumn{4}{|l|}{ Marital status, $n(\%)$} \\
\hline Single & $123(98.4)$ & $2(1.6)$ & \multirow[t]{4}{*}{$0.030^{3}$} \\
\hline Married & $452(99.6)$ & $2(0.4)$ & \\
\hline Divorced/Separated & $62(95.4)$ & $3(4.6)$ & \\
\hline Widowed & $15(100.0)$ & $0(0)$ & \\
\hline \multicolumn{4}{|l|}{ Living status, $n$ (\%) } \\
\hline Alone & $51(98.1)$ & $1(1.9)$ & \multirow[t]{3}{*}{$0.004^{3}$} \\
\hline With a family & $562(99.5)$ & $3(0.5)$ & \\
\hline With a partner & 39 (92.9) & $3(7.1)$ & \\
\hline \multicolumn{4}{|l|}{ Having children, $n(\%)$} \\
\hline Yes & $521(98.9)$ & $6(1.1)$ & \multirow[t]{2}{*}{$>0.999^{3}$} \\
\hline No & $131(99.2)$ & $1(0.8)$ & \\
\hline ACE $1-10^{*}$ score, $M(S D)$ & $0.75(1.48)$ & $1.57(1.27)$ & $0.020^{1}$ \\
\hline ACE $1-13^{* *}$ score, $M(S D)$ & $1.07(1.68)$ & $2.00(1.41)$ & $0.027^{1}$ \\
\hline \multicolumn{4}{|c|}{ ACE cumulative score on ACE (13) questionnaire } \\
\hline$<4$ of 13 & $599(99.0)$ & $6(1.0)$ & \multirow[t]{2}{*}{$0.452^{3}$} \\
\hline 4 and more of 13 & $53(98.1)$ & $1(1.9)$ & \\
\hline GSE, M (SD) & $31.62(4.80)$ & $29.00(5.07)$ & $0.130^{1}$ \\
\hline
\end{tabular}

$P$ - level of statistical significance, $M$ - mean, SD - standard deviation. ${ }^{1} M a n n$-Whitney $U$ test. ${ }^{2} \chi^{2}$ test. ${ }^{3}$ Fisher's exact test. ${ }^{*} N u m b e r$ of ACEs assessed with the ACE Study questionnaire. ${ }^{* *}$ Number of ACEs assessed with the ACE (13) questionnaire. ACE - adverse childhood experience, GSE - generalized self-efficacy assessed with the Generalized Self-Efficacy Scale.

B. Logistic regression model for lifetime suicide attempt - the model was not statistically significant $\left[\chi^{2}(7)=125.2\right.$; $p=0.085]$ - none of the variables (i.e., marital and living status, ACEs) were significant explanatory variables for risk of a lifetime suicide attempt 
Differences in social variables, demographics, adverse childhood experience scores, and Generalized Self-Efficacy Scale scores between individuals who report vs. do not report each of the six outcome measures

Part A of Tables III-VIII presents a comparison of individuals who reported vs. did not report experiencing each of the six outcome measures (i.e., lifetime suicide attempt, self-mutilation, potential problem drinking, street drug use, and ever visiting a psychologist/psychotherapist or a psychiatrist) by social and demographic variables, generalized self-efficacy, and the number of self-reported ACEs. Characteristics that significantly differed between groups (i.e., reported vs. not reported) were entered into multiple logistic regression models to identify independent variables that were significantly associated with each outcome (Part B of Tables III-VIII). When two or all three of the tested variables (i.e., ACE Study questionnaire score, ACE (13) questionnaire score, ACE (13) cumulative score $\geq 4$ ) were significantly associated with a given outcome variable, a separate logistic regression model was built for each to test for possible associations with the outcome measure.

\section{Relationship between adverse childhood experience score and each outcome measure: logistic regression models}

\section{Lifetime suicide attempt}

The logistic regression model for lifetime suicide attempt was not significant $\left[\chi^{2}(7)=125.2\right.$; $p=0.085]$. In particular, we found that individuals who reported vs. did not report at least one lifetime suicide attempt differed in marital and living status, ACE Study questionnaire score, and ACE (13) questionnaire score (Table III A). However, these variables were not significantly associated with the outcome variable (Table III B).

\section{Lifetime self-mutilation}

The association between ACEs and lifetime self-mutilation is presented in Table IV B.

An ACE score of at least 4 on the ACE (13) questionnaire was associated with a 10.8-fold increase in likelihood of lifetime self-mutilation $(p=0.003)$ when compared to individuals scoring $<4$.

\section{Lifetime potential problem drinking}

Logistic regression identified an association between male sex and an increased prevalence of lifetime potential problem drinking (see Table $V$ B) with an OR of $0.46,0.44$, and 0.49 for the ACE Study questionnaire (Model 1), ACE (13) questionnaire (Model 2) and ACE score of $\geq 4$ vs. $<4$ on the ACE (13) questionnaire (Model 3), respectively. Models $1-3$ were associated with a $39 \%$ ( $p<0.001), 37 \%(p<0.001)$, and 326\% ( $p<0.001)$ increased likelihood of lifetime potential problem drinking, respectively.

\section{Lifetime use of street drugs}

Logistic regression showed that lifetime street drug use was more prevalent among male study participants (OR 0.24 and 0.23 for Models 1 and 2, respectively; Table VI B). For each increase in score on both the ACE Study questionnaire (Table VI B, Model 1) and the ACE (13) questionnaire (Table VI B, Model 2), the lifetime risk of street drug use increased by $32 \%(p=0.012)$ and $28 \%(p=0.014)$, respectively.

\section{Lifetime visit to a psychologist/ psychotherapist}

The association between ACE score and ever visiting psychologist/psychotherapist is presented in Table VII B (Models 1-3). There was an association between marital status and lifetime visit to a psychologist/psychotherapist. In particular, single individuals were less likely to visit a psychologist/psychotherapist than widowed individuals $(O R=0.11,0.11$, and 0.12 for Models $1-3$, respectively). Married individuals were also less likely than widowed individuals to visit a psychologist/psychotherapist ( $O R=0.11,0.11$, and 0.12 , for Models 1-3, respectively). Every increase in ACE score was associated with a $45 \%(p<0.001)$, $38 \%(p<0.001)$, and $572 \%(p<0.001)$ increased likelihood of visiting a psychologist/psychotherapist, as measured using the ACE Study questionnaire (Table VII B, Model 1), ACE (13) questionnaire (Table VII B, Model 2), and ACE (13) score of $\geq 4$ (Table VII B, Model 3), respectively.

\section{Lifetime visit to a psychiatrist}

There was an association between marital status and lifetime visit to a psychiatrist (Table VIII B). In particular, single individuals were less likely to visit a psychologist/psychotherapist than widowed individuals $(\mathrm{OR}=0.1,0.09$, and 0.1 for Models 1-3, respectively). Married individuals were also less likely than widowed individuals to visit a psychiatrist $(O R=0.11,0.11$, and 0.12 , for Models $1-3$, respectively). Every increase in ACE score was associated with a 49\% ( $p<0.001), 42 \%$ $(p<0.001)$, and $671 \%(p<0.001)$ increased likelihood of visiting a psychiatrist, as measured using the ACE Study questionnaire (Table VIII B, Model 1), ACE (13) questionnaire (Table VIII B, Model 2), and ACE (13) score of $\geq 4$ on the ACE (13) questionnaire (Table VIII B, Model 3), respectively. 
Table IV. Self-mutilation

A. Comparison of individuals with $(n=6)$ and without $(n=653)$ a lifetime history of self-mutilation

\begin{tabular}{|c|c|c|c|}
\hline \multirow[t]{2}{*}{ Parameter } & \multicolumn{2}{|c|}{ Self-mutilation } & \multirow[t]{2}{*}{$P$} \\
\hline & No $(n=653)$ & Yes $(n=6)$ & \\
\hline Age at survey, M (SD) [years] & $43.39(8.59)$ & $42.50(9.73)$ & $0.588^{1}$ \\
\hline \multicolumn{4}{|l|}{ Sex, $n(\%)$} \\
\hline Female & $559(99.1)$ & $5(0.9)$ & \multirow[t]{2}{*}{$>0.999^{3}$} \\
\hline Male & $94(98.9)$ & $1(1.1)$ & \\
\hline \multicolumn{4}{|l|}{ Place of living, $n$ (\%) } \\
\hline Village & $188(99.5)$ & $1(0.5)$ & \multirow[t]{3}{*}{$0.766^{3}$} \\
\hline City of $<50000$ inhabitants & $153(98.7)$ & $2(1.3)$ & \\
\hline City of $\geq 50000$ inhabitants & $312(99.0)$ & $3(1.0)$ & \\
\hline \multicolumn{4}{|l|}{ Educational level, $n$ (\%) } \\
\hline Elementary & $7(100.0)$ & $0(0.0)$ & \multirow[t]{4}{*}{$>0.999^{3}$} \\
\hline Vocational & $11(100.0)$ & $0(0.0)$ & \\
\hline Secondary & $325(99.1)$ & $3(0.9)$ & \\
\hline University degree & $310(99.0)$ & $3(1.0)$ & \\
\hline \multicolumn{4}{|l|}{ Occupational status, $n$ (\%) } \\
\hline Employed & $637(99.1)$ & $6(0.9)$ & \multirow[t]{3}{*}{$>0.999^{3}$} \\
\hline Unemployed & $8(100.0)$ & $0(0.0)$ & \\
\hline Student & $8(100.0)$ & $0(0.0)$ & \\
\hline \multicolumn{4}{|l|}{ Marital status, $n(\%)$} \\
\hline Single & $123(98.4)$ & $2(1.6)$ & \multirow[t]{4}{*}{$0.376^{3}$} \\
\hline Married & $451(99.3)$ & $3(0.7)$ & \\
\hline Divorced/separated & $64(98.5)$ & $1(1.5)$ & \\
\hline Widowed & $15(100.0)$ & $0(0.0)$ & \\
\hline \multicolumn{4}{|l|}{ Living status, $n(\%)$} \\
\hline Alone & $51(98.1)$ & $1(1.9)$ & \multirow[t]{3}{*}{$0.604^{3}$} \\
\hline With a family & $560(99.1)$ & $5(0.9)$ & \\
\hline With a partner & $42(100.0)$ & $0(0.0)$ & \\
\hline \multicolumn{4}{|l|}{ Having children, $n$ (\%) } \\
\hline Yes & $523(99.2)$ & $4(0.8)$ & \multirow[t]{2}{*}{$0.345^{3}$} \\
\hline No & $130(98.5)$ & $2(1.5)$ & \\
\hline ACE $1-10^{*}$ score, M (SD) & $0.75(1.48)$ & $1.67(1.86)$ & $0.182^{1}$ \\
\hline ACE $1-13^{* *}$ score, M (SD) & $1.07(1.67)$ & $2.50(2.43)$ & $0.127^{1}$ \\
\hline \multicolumn{4}{|c|}{ ACE cumulative score on ACE (13) questionnaire } \\
\hline$<4$ of 13 & $602(99.5)$ & $3(0.5)$ & \multirow[t]{2}{*}{$0.009^{3}$} \\
\hline 4 and more of 13 & $51(94.4)$ & $3(5.6)$ & \\
\hline GSE M (SD) & $31.60(4.82)$ & $30.83(2.14)$ & $0.611^{1}$ \\
\hline
\end{tabular}

$P$ - level of statistical significance. ${ }^{1}$ Mann-Whitney U Test. ${ }^{2}{ }^{2}{ }^{2}$ test. ${ }^{3}$ Fisher's exact test. ${ }^{*}$ Number of ACEs assessed with the ACE Study questionnaire. ${ }^{* *} N u m b e r$ of ACEs assessed with the ACE (13) questionnaire. ACE - adverse childhood experience, GSE - generalized selfefficacy assessed with the Generalized Self-Efficacy Scale. 
B. Logistic regression model for lifetime self-mutilation

\begin{tabular}{|lccccccccc|}
\hline & B & SE & Z & $P$ & Exp(B) & Cox-Snell $R^{2}$ & Nagelkerke's $R^{2}$ & $\chi^{2}$ & $P$ \\
\hline $\begin{array}{l}\text { ACE cumulative score on } \\
\text { ACE (13) questionnaire }\end{array}$ & 2.47 & 0.83 & 8.86 & 0.003 & 11.80 & 0.011 & 0.112 & 7.34 & 0.007 \\
\hline
\end{tabular}

$B$ - unstandardized coefficient, SE - standard error, $Z$ - Wald test value, $p$ - level of statistical significance, Exp $(B)-$ odds ratio, $\chi^{2}-$ chi square test. "ACEs assessed with the ACE Study questionnaire. *ACEs assessed with the ACE (13) questionnaire.

\section{Relationship between generalized} self-efficacy and outcomes variables

Generalized self-efficacy was significantly lower in individuals who visited a psychologist/ psychotherapist at least once in his/her lifetime (Table VII A), but generalized self-efficacy was not a significant predictor of ever visiting a psychologist/psychotherapist (Table VII B, Model 1, 2, 3).

\section{Generalized self-efficacy and testing for significant explanatory variables in variability: linear regression model}

Furthermore, we tested whether ACEs, selected social variables and demographics, and final outcomes were significantly associated/correlated with generalized self-efficacy (Table IX). We found that male study participants had significantly higher generalized self-efficacy as compared to females (Table IX). In addition, a higher number of self-reported ACE categories (measured using the ACE (13) questionnaire) was correlated with lower GSES score across the whole study sample. Educational level, occupational status, and lifetime history of visiting a psychologist/psychotherapist were significantly associated with generalized self-efficacy. In particular, individuals with vocational education scored higher on the GSES than those with a secondary education ( $p=0.038$ ) or a university degree $(p=0.029)$. Students scored higher on the GSES than employed individuals ( $p=0.008)$. Study participants reporting visiting a psychologist/psychotherapist during his/her lifetime scored lower on the GSES than individuals who reported never visiting a psychologist/ psychotherapist ( $p=0.023$ ) (Table IX).

However, in the linear regression model, sex and the number of ACE categories (via the ACE (13) questionnaire) were the only remaining variables that significantly explained variability in generalized self-efficacy (Table $X$ ). The model for the whole study group explained $8.2 \%$ of the variability in generalized self-efficacy. Of the $8.2 \%$ of variability explained, ACEs explained $1.2 \%$. The linear regression model for variability in generalized self-efficacy in male study participants was not significant. The model for female participants, in contrast, reached significance and explained $1.7 \%$ of the variability in the GSES. Of the $1.7 \%$ of variability explained, ACEs explained $1.3 \%$ of the variability in generalized self-efficacy (Table X).

\section{Discussion}

The present study aimed to assess (1) whether ACEs are significantly and independently associated with any of the following six lifetime outcomes in the general Polish population: suicide attempt, self-mutilation, potential problem drinking, street drug use, visit to a psychologist/psychotherapist, visit to a psychiatrist. (2) The second aim was to test whether ACEs significantly explain the variability in generalized self-efficacy in the study sample. The final study sample included 659 healthy volunteers recruited from the general population in Poland. Exposure to ACEs was found to increase the likelihood of all the analyzed outcome variables except lifetime suicide attempt. Thirteen ACE categories explained $1.2 \%$ of the variability in generalized self-efficacy in the whole study sample, which remained significant when females were tested separately, and explained 1.7\% of variability.

Exposure to at least one of the 13 ACE categories was reported by $48.1 \%$ of the final sample taken from the general population (Figure $1 \mathrm{~A}$ ). Of the adult healthy volunteers who had (1) never been diagnosed with a mental disorder (according to the ICD-10 [11]), (2) a negative lifetime history of suicide attempt and (3) self-mutilation and (4) did not obtain Alcohol Use Disorders Identification Test (AUDIT) scores [12] indicating alcohol abuse [11] or alcohol dependence [11], only $31 \%$ reported exposure to at least one ACE category [13]. When the ACE (13) questionnaire was used in a group of patients with alcohol dependence, about $85 \%$ reported experiencing at least one of the possible ACE categories [7]. In a more recent study, ACE (13) questionnaire scores were inversely correlated with generalized self-efficacy (as measured with the GSES) and health-promoting behaviors (measured with the Health Behavior Inventory) [10]. Moreover, variability in ACE (13) scores accounted for $3.2 \%$ of the variability in generalized self-efficacy and $3.9 \%$ of the variability in Health Behavior Inventory (HBI) among patients with alcohol dependence [7]. To summarize, ACEs appear to be more frequently reported and are of higher importance in populations with health-harming behaviors or with diagnosed mental disorders [7]. As compared to females, males in our study sample reported exposure to fewer ACE categories (Figure 1 B), showed higher gener- 
Table V. Potential problem drinking

A. Comparison of the study group individuals with $(n=78)$ a potential problem drinking (scoring $\geq 1$ point with the CAGE questionnaire) and without $(n=581)$ problem drinking (scoring 0 points with the CAGE questionnaire)

\begin{tabular}{|c|c|c|c|}
\hline \multirow[t]{2}{*}{ Parameter } & \multicolumn{2}{|c|}{ Potential problem drinking } & \multirow[t]{2}{*}{$i$} \\
\hline & No $(n=581)$ & Yes $(n=78)$ & \\
\hline Age at survey, M (SD) & $43.41(8.50)$ & $43.14(9.33)$ & $0.853^{1}$ \\
\hline \multicolumn{4}{|l|}{ Sex, $n(\%)$} \\
\hline Female & $503(89.2)$ & $61(10.8)$ & \multirow[t]{2}{*}{$0.048^{2}$} \\
\hline Male & $78(82.1)$ & $17(17.9)$ & \\
\hline \multicolumn{4}{|l|}{ Place of living, $n(\%)$} \\
\hline Village & $175(92.6)$ & $14(7.4)^{\star}$ & \multirow[t]{3}{*}{$0.017^{2}$} \\
\hline City of $<50000$ inhabitants & $128(82.6)$ & $27(17.4)^{\star}$ & \\
\hline City of $\geq 50000$ inhabitants & $278(88.3)$ & $37(11.7)$ & \\
\hline \multicolumn{4}{|l|}{ Educational level, $n$ (\%) } \\
\hline Elementary & $6(85.7)$ & $1(14.3)$ & \multirow[t]{4}{*}{$0.433^{3}$} \\
\hline Vocational & $10(90.9)$ & $1(9.1)$ & \\
\hline Secondary & $295(89.9)$ & $33(10.1)$ & \\
\hline University degree & $270(86.3)$ & $43(13.7)$ & \\
\hline \multicolumn{4}{|l|}{ Occupational status, $n(\%)$} \\
\hline Employed & $566(88.0)$ & $77(12.0)$ & \multirow[t]{3}{*}{$0.844^{3}$} \\
\hline Unemployed & $7(87.5)$ & $1(12.5)$ & \\
\hline Student & $8(100.0)$ & $0(0.0)$ & \\
\hline \multicolumn{4}{|l|}{ Marital status, $n(\%)$} \\
\hline Single & $108(86.4)$ & $17(13.6)$ & \multirow[t]{4}{*}{$0.112^{3}$} \\
\hline Married & $408(89.9)$ & $46(10.1)$ & \\
\hline Divorced/separated & $53(81.5)$ & $12(18.5)$ & \\
\hline Widowed & $12(80.0)$ & $3(20.0)$ & \\
\hline \multicolumn{4}{|l|}{ Living status, $n$ (\%) } \\
\hline Alone & $40(76.9)$ & $12(23.1)^{*}$ & \multirow[t]{3}{*}{$0.042^{3}$} \\
\hline With a family & $504(89.2)$ & $61(10.8)^{*}$ & \\
\hline With a partner & $37(88.1)$ & $5(11.9)$ & \\
\hline \multicolumn{4}{|l|}{ Having children, $n(\%)$} \\
\hline Yes & $466(88.4)$ & $61(11.6)$ & \multirow[t]{2}{*}{$0.678^{2}$} \\
\hline No & $115(87.1)$ & $17(12.9)$ & \\
\hline ACE $1-10^{*}$ score, $M(S D)$ & $0.64(1.34)$ & $1.64(2.06)$ & $<0.001^{1}$ \\
\hline ACE $1-13^{* *}$ score, $M(S D)$ & $0.94(1.53)$ & $2.13(2.33)$ & $<0.001^{1}$ \\
\hline \multicolumn{4}{|c|}{ ACE cumulative score on ACE (13) questionnaire } \\
\hline$<4$ of 13 & $544(89.9)$ & $61(10.1)$ & \multirow[t]{2}{*}{$<0.001^{3}$} \\
\hline 4 and more of 13 & $37(68.5)$ & $17(31.5)$ & \\
\hline GSE M (SD) & $31.64(4.85)$ & $31.22(4.50)$ & $0.418^{1}$ \\
\hline
\end{tabular}


B. Logistic regression model for potential problem drinking

\begin{tabular}{|c|c|c|c|c|c|c|c|c|c|}
\hline MODEL 1 & B & SE & $Z$ & $P$ & $\operatorname{Exp}(B)$ & Cox-Snell $R^{2}$ & Nagelkerke's $R^{2}$ & $\chi^{2}$ & $P$ \\
\hline Sex & -0.78 & 0.31 & 6.30 & 0.012 & 0.46 & 0.050 & 0.098 & 34.14 & $<0.001$ \\
\hline Living status & & & 4.80 & 0.091 & & & & & \\
\hline Alone & 0.73 & 0.60 & 1.47 & 0.225 & 2.07 & & & & \\
\hline With family & -010 & 0.51 & 0.04 & 0.849 & 0.91 & & & & \\
\hline ACE $1-10^{*}$ score & 0.33 & 0.06 & 26.65 & $<0.001$ & 1.39 & & & & \\
\hline
\end{tabular}

$B$ - unstandardized coefficient, SE - standard error, $Z$ - Wald test value, $p$ - level of statistical significance, Exp(B) - odds ratio, $\chi^{2}-$ chi square test. *ACEs assessed with the ACE Study questionnaire.

\begin{tabular}{|c|c|c|c|c|c|c|c|c|c|}
\hline MODEL 2 & B & SE & $Z$ & $P$ & $\operatorname{Exp}(B)$ & Cox-Snell $R^{2}$ & Nagelkerke's $R^{2}$ & $\chi^{2}$ & $P$ \\
\hline Sex & -0.82 & 0.32 & 6.72 & 0.010 & 0.44 & 0.054 & 0.105 & 36.74 & $<0.001$ \\
\hline Living status & & & 4.53 & 0.104 & & & & & \\
\hline Alone & 0.76 & 0.61 & 1.54 & 0.214 & 2.13 & & & & \\
\hline With family & -0.06 & 0.51 & 0.01 & 0.906 & 0.94 & & & & \\
\hline ACE $1-13^{* *}$ score & 0.31 & 0.06 & 28.43 & $<0.001$ & 1.37 & & & & \\
\hline
\end{tabular}

$B$ - unstandardized coefficient, SE - standard error, $Z$ - Wald test value, $p$ - level of statistical significance, Exp(B) - odds ratio, $\chi^{2}-\operatorname{chi}$ square test. *ACEs assessed with the ACE (13) questionnaire.

\begin{tabular}{|c|c|c|c|c|c|c|c|c|c|}
\hline MODEL 3 & B & SE & $Z$ & $P$ & $\operatorname{Exp}(B)$ & Cox-Snell $R^{2}$ & Nagelkerke's $R^{2}$ & $\chi^{2}$ & $P$ \\
\hline Sex & -0.70 & 0.31 & 5.13 & 0.024 & 0.49 & 0.039 & 0.075 & 25.90 & $<0.001$ \\
\hline Living status & & & 5.06 & 0.080 & & & & & \\
\hline Alone & 0.77 & 0.59 & 1.69 & 0.193 & 2.17 & & & & \\
\hline With family & -0.06 & 0.51 & 0.01 & 0.912 & 0.95 & & & & \\
\hline $\begin{array}{l}\text { ACE cumulative } \\
\text { score on } \\
\text { ACE (13) } \\
\text { questionnaire }\end{array}$ & 1.45 & 0.33 & 19.28 & $<0.001$ & 4.26 & & & & \\
\hline
\end{tabular}

alized self-efficacy (Table IX), and were less likely to seek the professional help of a psychologist/ psychiatrist (Table VII A). The overrepresentation of females in our study group does not limit the interpretation of the regression models for final outcome variables, and the variability in generalized self-efficacy, as sex was included in all calculations as a control variable when it differed between individuals reporting vs. not reporting each final outcome or when it was associated with GSES score. Male sex increased the likelihood of lifetime potential problem drinking by $51-56 \%$ (Table V B, Model 1-3), and of lifetime street drug use by $76-77 \%$ (Table VI B, Model 1-2). These rates are in line with epidemiological findings of the World Health Organization (WHO) and the World Drug Report $[14,15]$. As reported by the WHO [14], in 2016, $12.8 \%$ of the Polish population aged $\geq 15$ years had alcohol use disorders, comprising $2.2 \%$ with alcohol dependence and $10.6 \%$ with harmful use. In our study group, $11.6 \%$ of individuals were identified as potential problem drinkers. ZielińskaDanch et al. (2019) tested the Polish population aged 15-25 and found that males were more than twice as likely as females to be current or ever waterpipe tobacco smokers, and those who reported waterpipe use were also more frequently street drugs and alcohol users [16]. Females reported seeking the help of a psychologist/psychiatrist more frequently than males (Table VII A), but sex was not significantly associated with the likelihood of ever visiting a psychologist/psychotherapist (Table VII B). However, the overrepresentation of females in our study group may limit the interpretation of differences in reporting of each ACE category (Figure 1 B). It would be more realistic to compare the prevalence of ACE categories between an equivalent number of males and fe- 
Table VI. Street drug use

A. Comparison of study group individuals with $(n=18)$ and without $(n=641)$ a lifetime history of street drug use

\begin{tabular}{|c|c|c|c|}
\hline \multirow[t]{2}{*}{ Parameter } & \multicolumn{2}{|c|}{ Street drug use } & \multirow{2}{*}{$P$} \\
\hline & No $(n=641)$ & Yes $(n=18)$ & \\
\hline Age at survey, M (SD) [years] & $43.47(8.57)$ & $40.00(8.94)$ & $0.047^{1}$ \\
\hline \multicolumn{4}{|l|}{ Sex, $n(\%)$} \\
\hline Female & $553(98.0)$ & $11(2.0)$ & \multirow[t]{2}{*}{$0.009^{3}$} \\
\hline Male & $88(92.6)$ & $7(7.4)$ & \\
\hline \multicolumn{4}{|l|}{ Place of living, $n(\%)$} \\
\hline Village & $185(97.9)$ & $4(2.1)$ & \multirow[t]{3}{*}{$0.284^{3}$} \\
\hline City of $<50,000$ inhabitants & $153(98.7)$ & $2(1.3)$ & \\
\hline City of $\geq 50,000$ inhabitants & $303(96.2)$ & $12(3.8)$ & \\
\hline \multicolumn{4}{|l|}{ Educational level, $n$ (\%) } \\
\hline Elementary & $7(100.0)$ & $0(0)$ & \multirow[t]{4}{*}{$0.306^{3}$} \\
\hline Vocational & $11(100.0)$ & $0(0)$ & \\
\hline Secondary & $323(98.5)$ & $5(1.5)$ & \\
\hline University degree & $300(96.2)$ & $12(3.8)$ & \\
\hline \multicolumn{4}{|l|}{ Occupational status, $n(\%)$} \\
\hline Employed & $625(97.2)$ & $18(2.8)$ & \multirow[t]{3}{*}{$>0.999^{3}$} \\
\hline Unemployed & $8(100.0)$ & $0(0.0)$ & \\
\hline Student & $8(100.0)$ & $0(0.0)$ & \\
\hline \multicolumn{4}{|l|}{ Marital status, $n(\%)$} \\
\hline Single & $122(97.6)$ & $3(2.4)$ & \multirow[t]{4}{*}{$>0.999^{3}$} \\
\hline Married & $441(97.1)$ & $13(2.9)$ & \\
\hline Divorced/separated & $63(96.9)$ & $2(3.1)$ & \\
\hline Widowed & $15(100.0)$ & $0(0.0)$ & \\
\hline \multicolumn{4}{|l|}{ Living status, $n(\%)$} \\
\hline Alone & $51(98.1)$ & $1(1.9)$ & \multirow[t]{3}{*}{$>0.999^{3}$} \\
\hline With a family & $549(97.2)$ & $16(2.8)$ & \\
\hline With a partner & $41(97.6)$ & $1(2.4)$ & \\
\hline \multicolumn{4}{|l|}{ Having children, $n(\%)$} \\
\hline Yes & $513(97.3)$ & $14(2.7)$ & \multirow[t]{2}{*}{$0.768^{3}$} \\
\hline No & $128(97.0)$ & $4(3.0)$ & \\
\hline ACE $1-10^{*}$ score, M (SD) & $0.73(1.47)$ & $1.50(1.82)$ & $0.009^{1}$ \\
\hline ACE $1-13^{* *}$ score, $M(S D)$ & $1.06(1.67)$ & $1.89(1.99)$ & $0.021^{1}$ \\
\hline \multicolumn{4}{|c|}{ ACE cumulative score on ACE (13) questionnaire*** } \\
\hline$<4$ of 13 & $591(97.7)$ & $14(2.3)$ & \multirow[t]{2}{*}{$0.052^{3}$} \\
\hline 4 and more of 13 & $50(92.6)$ & $4(7.4)$ & \\
\hline GSE M (SD) & $31.58(4.82)$ & $31.83(4.41)$ & $0.933^{1}$ \\
\hline
\end{tabular}

$P$ - level of statistical significance, $M-$ mean, $S D$ - standard deviation. ${ }^{1} M a n n-W h i t n e y ~ U$ test. ${ }^{2} \chi^{2}$ test. ${ }^{3}$ Fisher's exact test. ${ }^{*}$ Number of ACEs assessed with the ACE Study questionnaire. **Number of ACEs assessed with the ACE (13) questionnaire. ACE - adverse childhood experience, GSE - generalized self-efficacy assessed with the Generalized Self-Efficacy Scale. ${ }^{* * *}<4$ vs. $\geq 4$ ACE categories self-reported on ACE (13) questionnaire. 
B. Logistic regression model predicting risk of lifetime street drug use

\begin{tabular}{|c|c|c|c|c|c|c|c|c|c|}
\hline MODEL 1 & B & SE & $Z$ & $P$ & $\operatorname{Exp}(B)$ & Cox-Snell $R^{2}$ & Nagelkerke's $R^{2}$ & $\chi^{2}$ & $P$ \\
\hline Age & -0.02 & 0.03 & 0.91 & 0.341 & 0.98 & 0.019 & 0.084 & 12.44 & 0.006 \\
\hline Sex & -1.45 & 0.54 & 7.27 & 0.007 & 0.24 & & & & \\
\hline ACE score $1-10^{*}$ & 0.28 & 0.11 & 6.29 & 0.012 & 1.32 & & & & \\
\hline
\end{tabular}

$B$ - unstandardized coefficient, SE - standard error, $Z$ - Wald test value, $p$ - level of statistical significance, Exp(B) - odds ratio (95\% confidence interval), $\chi^{2}$-chi square test, ACE - adverse childhood experience. *Number of ACEs assessed with the ACE Study questionnaire. ${ }^{* *}$ Number of ACEs assessed with the ACE (13) questionnaire.

\begin{tabular}{|c|c|c|c|c|c|c|c|c|c|}
\hline MODEL 2 & B & SE & $z$ & $P$ & $\operatorname{Exp}(B)$ & Cox-Snell $R^{2}$ & Nagelkerke's $R^{2}$ & $\chi^{2}$ & $P$ \\
\hline Age & -0.03 & 0.03 & 0.92 & 0.337 & 0.98 & 0.019 & 0.084 & 12.33 & 0.006 \\
\hline Sex & -1.46 & 0.54 & 7.39 & 0.007 & 0.23 & & & & \\
\hline ACE score $1-13^{*}$ & 0.25 & 0.10 & 6.06 & 0.014 & 1.28 & & & & \\
\hline
\end{tabular}

$B$ - unstandardized coefficient, SE - standard error, $Z$ - Wald test value, $p$ - level of statistical significance, Exp(B) - odds ratio, $\chi^{2}-c h i$ square test, ACE - adverse childhood experience. *Number of ACEs assessed with the ACE (13) questionnaire.

males, and sex groups may be matched for social and demographic variables. Overall, males in our sample were less likely to report exposure to physical abuse (ACE 2), potential drinking/alcoholic/ street drug use of a household member (ACE 8), and witnessing a family member's death due to any cause except for completed suicide (ACE 12) than females (Figure $1 \mathrm{~B}$ ). There was no difference in reported rates of sexual abuse (ACE 3) between males and females in our study (Figure 1 B). Previous research suggests that, relative to males, females report higher rates of childhood adversity, likely due to higher rates of sexual abuse [17]. In a previous study by our group, we observed a higher rate of self-reported sexual abuse using the ACE Study questionnaire in a clinical samples of female patients with alcohol dependence and with a depression disorder (i.e., $23.9 \%$ and $19 \%$, respectively; data not published yet). Thus, we predict that, with an increasing number of individuals who qualified for the present study from the general population, the number of individuals with serious mental disorders would raise the prevalence of self-reported ACE categories. In the present study, generalized self-efficacy was not significantly associated with any of the six outcome variables (Table III-VIII B). We found that generalized self-efficacy decreased as ACE (13) questionnaire score increased. Further, ACE (13) questionnaire score explained $1.2 \%$ of the variability in generalized self-efficacy in the whole study sample, and this effect remained significant in females and explained $1.7 \%$ of this variability. Importantly, ACEs do not necessarily have an adverse impact on future social abilities, health-harming behaviors, and mental or physical disorders. For example, not all of the siblings raised in the same dysfunctional household suffer from the lifetime adverse effects of childhood adversity. This may be due to a supportive change in environment during their childhood or young adulthood (e.g., from psychotherapy, removal, or meeting supportive adults), other protective factors, or individual differences in gene-environment-epigenetic interaction [13, 18, 19]. Radziwiłłowicz found that a critical number of ACEs (at least 3 in that study) is necessary for increasing the risk of future mental disorders such as depression, and that such risk increases when ACEs are of a repetitive character [20, 21]. Three additional ACE categories implemented in the current study were included, i.e. witnessing a family member's suicide attempt (ACE 11), death due to any cause except for completed suicide (ACE 12), or a stranger's death (ACE 13). However, the former two ACE categories may also be associated with loss of an attachment figure, or due to the presence of potential risk factors that may worsen the course of bereavement [21]. Several studies have observed that it is not only the number of ACEs, but also the kind of ACE category (independent from other reported ACEs) that modulates the risk of depression, alcohol dependence, and suicide $[4,5,21]$. We did not assess a possible influence of any particular kind of ACE category, but of the number of ACE categories and their Cumulative effect when reporting at least 4 ACEs. Indeed, an ACE (13) questionnaire score of at least 4 (vs. < 4) was associated with a 10.8-fold increased likelihood of self-mutilation, a 3.26-fold increase in potential problem drinking, a 5.72-fold increase in likelihood of visiting a psychologist/psychotherapist, and a 6.71-fold increased likelihood of visiting a psychiatrist.

In the study, we did not screen for lifetime mental disorders but rather asked about lifetime visits to a psychiatrist or psychologist/psycho- 
Table VII. Visit to a psychologist/psychotherapist

A. Comparison of study group individuals with $(n=61)$ and without $(n=598)$ a lifetime history of visiting a psychotherapist

\begin{tabular}{|c|c|c|c|}
\hline \multirow[t]{2}{*}{ Parameter } & \multicolumn{2}{|c|}{ Lifetime history of visiting a psychotherapist } & \multirow[t]{2}{*}{$P$} \\
\hline & No $(n=598)$ & Yes $(n=61)$ & \\
\hline Age at survey, M (SD) [years] & $43.36(8.69)$ & $43.56(7.64)$ & $0.603^{1}$ \\
\hline \multicolumn{4}{|l|}{ Sex, $n(\%)$} \\
\hline Female & $506(89.7)$ & $58(10.3)$ & \multirow[t]{2}{*}{$0.027^{2}$} \\
\hline Male & $92(96.8)$ & $3(3.2)$ & \\
\hline \multicolumn{4}{|l|}{ Place of living, $n(\%)$} \\
\hline Village & $174(92.1)$ & $15(7.9)$ & \multirow[t]{3}{*}{$0.580^{2}$} \\
\hline City of $<50,000$ inhabitants & $142(91.6)$ & $13(8.4)$ & \\
\hline City of $\geq 50,000$ inhabitants & $282(89.5)$ & $33(10.5)$ & \\
\hline \multicolumn{4}{|l|}{ Educational level, $n(\%)$} \\
\hline Elementary & $6(85.7)$ & $1(14.3)$ & \multirow[t]{4}{*}{$0.816^{3}$} \\
\hline Vocational & $10(90.9)$ & $1(9.1)$ & \\
\hline Secondary & $298(90.9)$ & $30(9.1)$ & \\
\hline University degree & $284(90.7)$ & $29(9.3)$ & \\
\hline \multicolumn{4}{|l|}{ Occupational status, $n(\%)$} \\
\hline Employed & $582(90.5)$ & $61(9.5)$ & \multirow[t]{3}{*}{$>0.999^{3}$} \\
\hline Unemployed & $8(100.0)$ & $0(0.0)$ & \\
\hline Student & $8(100.0)$ & $0(0.0)$ & \\
\hline \multicolumn{4}{|l|}{ Marital status, $n(\%)$} \\
\hline Single & $117(93.6)$ & $8(6.4)$ & \multirow[t]{4}{*}{$<0.001^{3}$} \\
\hline Married & $423(93.2)$ & $31(6.8)$ & \\
\hline Divorced/separated & $48(73.8)$ & $17(26.2)$ & \\
\hline Widowed & $10(66.7)$ & $5(33.3)$ & \\
\hline \multicolumn{4}{|l|}{ Living status, $n(\%)$} \\
\hline Alone & $44(84.6)$ & $8(15.4)$ & \multirow[t]{3}{*}{$0.106^{3}$} \\
\hline With a family & $518(91.7)$ & $47(8.3)$ & \\
\hline With a partner & $36(85.7)$ & $6(14.3)$ & \\
\hline \multicolumn{4}{|l|}{ Having children, $n(\%)$} \\
\hline Yes & $474(89.9)$ & $53(10.1)$ & \multirow[t]{2}{*}{$0.157^{2}$} \\
\hline No & $124(93.9)$ & $8(6.1)$ & \\
\hline ACE $1-10^{*}$ score, $M(S D)$ & $0.63(1.31)$ & $1.97(2.29)$ & $<0.001^{1}$ \\
\hline ACE $1-13^{* *}$ score, $M(S D)$ & $0.95(1.51)$ & $2.41(2.53)$ & $<0.001^{1}$ \\
\hline \multicolumn{4}{|c|}{ ACE cumulative score on ACE (13) questionnaire } \\
\hline$<4$ of 13 & $563(93.1)$ & $42(6.9)$ & \multirow[t]{2}{*}{$<0.001^{3}$} \\
\hline 4 and more of 13 & $35(64.8)$ & $19(35.2)$ & \\
\hline GSE M (SD) & $31.72(4.78)$ & $30.34(4.88)$ & $0.023^{1}$ \\
\hline
\end{tabular}


B. Logistic regression model predicting risk of lifetime visit to a psychologist/psychotherapist

\begin{tabular}{|c|c|c|c|c|c|c|c|c|c|}
\hline MODEL 1 & B & SE & $z$ & $P$ & $\operatorname{Exp}(B)$ & Cox-Snell $R^{2}$ & Nagelkerke's $R^{2}$ & $\chi^{2}$ & $P$ \\
\hline Sex & 0.73 & 0.63 & 1.33 & 0.249 & 2.08 & 0.089 & 0.193 & 61.41 & $<0.001$ \\
\hline Marital status & & & 28.47 & $<0.001$ & & & & & \\
\hline Single & 2.17 & 0.69 & 10.02 & 0.002 & 0.11 & & & & \\
\hline Married & -2.17 & 0.59 & 13.33 & $<0.001$ & 0.11 & & & & \\
\hline Divorced/separated & -0.62 & 0.64 & 0.96 & 0.328 & 0.54 & & & & \\
\hline ACE $1-10^{*}$ score & 0.37 & 0.07 & 27.64 & $<0.001$ & 1.45 & & & & \\
\hline GSE & -0.04 & 0.03 & 1.79 & 0.181 & 0.96 & & & & \\
\hline
\end{tabular}

$B$ - unstandardized coefficient, SE - standard error, $Z$ - Wald test value, $p$ - level of statistical significance, Exp (B) - odds ratio, $\chi^{2}-$ chi square test. *Number of ACEs assessed with the ACE Study questionnaire. GSE-generalized self-efficacy assessed with the Generalized Self-Efficacy Scale.

\begin{tabular}{|c|c|c|c|c|c|c|c|c|c|}
\hline MODEL 2 & B & SE & $z$ & $P$ & $\operatorname{Exp}(B)$ & Cox-Snell $R^{2}$ & Nagelkerke's $R^{2}$ & $\chi^{2}$ & $P$ \\
\hline Sex & 0.69 & 0.63 & 1.18 & 0.277 & 1.99 & 0.087 & 0.189 & 59.87 & $<0.001$ \\
\hline Marital status & & & 28.03 & $<0.001$ & & & & & \\
\hline Single & -2.23 & 0.69 & 10.41 & 0.001 & 0.11 & & & & \\
\hline Married & -2.19 & 0.59 & 13.50 & $<0.001$ & 0.11 & & & & \\
\hline Divorced/separated & -0.69 & 0.64 & 1.16 & 0.281 & 0.50 & & & & \\
\hline ACE $1-13^{*}$ score & 0.32 & 0.06 & 25.82 & $<0.001$ & 1.38 & & & & \\
\hline GSE & -0.04 & 0.03 & 2.11 & 0.146 & 0.96 & & & & \\
\hline
\end{tabular}

$B$ - unstandardized coefficient, SE - standard error, Z - Wald test value, $p$ - level of statistical significance, Exp(B) - odds ratio, $\chi^{2}-$ chi square test. *Number of ACEs assessed with the ACE (13) questionnaire. GSE-generalized self-efficacy assessed with the Generalized Self-Efficacy Scale.

\begin{tabular}{|c|c|c|c|c|c|c|c|c|c|}
\hline MODEL 3 & B & SE & $z$ & $P$ & $\operatorname{Exp}(B)$ & Cox-Snell $R^{2}$ & Nagelkerke's $R^{2}$ & $\chi^{2}$ & $P$ \\
\hline Sex & 0.78 & 0.63 & 1.53 & 0.217 & 2.19 & 0.089 & 0.194 & 61.50 & $<0.001$ \\
\hline Marital status & & & 27.54 & $<0.001$ & & & & & \\
\hline Single & -2.15 & 0.69 & 9.64 & 0.002 & 0.12 & & & & \\
\hline Married & -2.12 & 0.60 & 12.39 & $<0.001$ & 0.12 & & & & \\
\hline Divorced/separated & -0.59 & 0.64 & 0.83 & 0.363 & 0.56 & & & & \\
\hline $\begin{array}{l}\text { ACE cumulative score on } \\
\text { ACE (13) questionnaire }\end{array}$ & 1.91 & 0.35 & 29.42 & $<0.001$ & 6.72 & & & & \\
\hline GSE & -0.04 & 0.03 & 1.78 & 0.183 & 0.96 & & & & \\
\hline
\end{tabular}

$B$ - unstandardized coefficient, SE - standard error, Z - Wald test value, $p$ - level of statistical significance, Exp(B) - odds ratio, $\chi^{2}-$ chi square test. GSE - generalized self-efficacy assessed with the Generalized Self-efficacy Scale.

therapist. Visiting a specialist points to seeking help for a mental problem by an individual. Of the 659 study participants, 62 (9.3\%) reported visiting a psychologist/psychotherapist during his/her lifetime, and 27 (4.0\%) reported visiting a psychiatrist. Twenty-two (3.3\%) reported having visited both a psychologist/psychotherapist and psychiatrist. None of the study participants reported experiencing three or four of the four final outcomes (i.e., lifetime suicide attempt, self-mutilation, potential problem drinking, street drug use). Experiencing two of the four final outcomes was reported by 13 individuals, and 83 individuals reported experiencing one. Notably, none of the individuals who reported a lifetime suicide attempt, self-mutilation, or street drug use had ever visited a psychiatrist, but a few reported visiting a psychologist/psychotherapist (3 of 7 , 1 of 6,3 of 18, respectively) (Table II). Of the 78 individuals with potential problem drinking, only 6 reported visiting a psychiatrist and 20 reported visiting a psychologist/psychotherapist (Table II). 
Table VIII. Visit to a psychiatrist

A. Comparison of the study group individuals with $(n=27)$ and without $(n=632)$ a lifetime history of visiting a psychiatrist

\begin{tabular}{|c|c|c|c|}
\hline \multirow[t]{2}{*}{ Parameter } & \multicolumn{2}{|c|}{ History of visit to a psychiatrist } & \multirow[t]{2}{*}{$P$} \\
\hline & No $(n=632)$ & Yes $(n=27)$ & \\
\hline Age at survey, M (SD) [years] & $43.29(8.59)$ & $45.37(8.60)$ & $0.380^{1}$ \\
\hline \multicolumn{4}{|l|}{ Sex, $n(\%)$} \\
\hline Female & $538(95.4)$ & $26(4.6)$ & \multirow[t]{2}{*}{$0.158^{3}$} \\
\hline Male & $94(98.9)$ & $1(1.1)$ & \\
\hline \multicolumn{4}{|l|}{ Place of living, $n(\%)$} \\
\hline Village & $184(97.4)$ & $5(2.6)$ & \multirow[t]{3}{*}{$0.338^{2}$} \\
\hline City of $<50000$ inhabitants & $146(94.2)$ & $9(5.8)$ & \\
\hline City of $\geq 50000$ inhabitants & $302(95.9)$ & $13(4.1)$ & \\
\hline \multicolumn{4}{|l|}{ Educational level, $n(\%)$} \\
\hline Elementary & $6(85.7)$ & $1(14.3)$ & \multirow[t]{4}{*}{$0.017^{3}$} \\
\hline Vocational & $11(100.0)$ & $0(0.0)$ & \\
\hline Secondary & $308(93.9)$ & $20(6.1)$ & \\
\hline University degree & $307(98.1)$ & $6(1.9)$ & \\
\hline \multicolumn{4}{|l|}{ Occupational status, $n(\%)$} \\
\hline Employed & $616(95.8)$ & $27(4.2)$ & \multirow[t]{3}{*}{$>0.999^{3}$} \\
\hline Unemployed & $8(100.0)$ & $0(0.0)$ & \\
\hline Student & $8(100.0)$ & $0(0.0)$ & \\
\hline \multicolumn{4}{|l|}{ Marital status, $n(\%)$} \\
\hline Single & $123(98.4)$ & $2(1.6)$ & \multirow[t]{4}{*}{$0.002^{3}$} \\
\hline Married & $439(96.7)$ & $15(3.4)$ & \\
\hline Divorced/separated & $57(87.7)$ & $8(2.3)$ & \\
\hline Widowed & $13(86.7)$ & $2(3.3)$ & \\
\hline \multicolumn{4}{|l|}{ Living status, $n(\%)$} \\
\hline Alone & $48(92.3)$ & $4(7.7)$ & \multirow[t]{3}{*}{$0.231^{3}$} \\
\hline With a family & $544(96.3)$ & $21(3.7)$ & \\
\hline With a partner & $40(95.2)$ & $2(4.8)$ & \\
\hline \multicolumn{4}{|c|}{ Having children (including dead child), $n$ (\%) } \\
\hline Yes & $503(95.4)$ & $24(4.6)$ & \multirow[t]{2}{*}{$0.237^{2}$} \\
\hline No & $129(97.7)$ & $3(2.3)$ & \\
\hline ACE $1-10^{*}$ score, M (SD) & $0.70(1.39)$ & $2.04(2.56)$ & $<0.001^{1}$ \\
\hline ACE $1-13^{* *}$ score, $M(S D)$ & $1.02(1.59)$ & $2.48(2.83)$ & $0.001^{1}$ \\
\hline \multicolumn{4}{|c|}{ ACE cumulative score on the ACE (13) questionnaire } \\
\hline$<4$ of 13 & $586(96.9)$ & $19(3.1)$ & \multirow[t]{2}{*}{$0.001^{3}$} \\
\hline 4 and more of 13 & $46(85.2)$ & $8(14.8)$ & \\
\hline GSE, M (SD) & $31.65(4.77)$ & $30.22(5.60)$ & $0.264^{1}$ \\
\hline
\end{tabular}


The role of adverse childhood experiences in risky behaviors, health care utilization, and generalized self-efficacy in the general adult Polish population

B. Logistic regression model predicting lifetime risk of visiting a psychiatrist

\begin{tabular}{|c|c|c|c|c|c|c|c|c|c|}
\hline MODEL 1 & B & SE & $z$ & $P$ & $\operatorname{Exp}(B)$ & Cox-Snell $R^{2}$ & Nagelkerke's $R^{2}$ & $\chi^{2}$ & $P$ \\
\hline Education level & & & 0.58 & 0.902 & & 0.084 & 0.182 & 57.82 & $<0.001$ \\
\hline Elementary & -0.99 & 1.43 & 0.49 & 0.484 & 0,37 & & & & \\
\hline Vocational & -0.33 & 1,12 & 0.09 & 0.770 & 0,72 & & & & \\
\hline Secondary & $<0.01$ & 0.29 & $<0.01$ & 0.992 & 1.00 & & & & \\
\hline Marital status & & & 29.93 & $<0.001$ & & & & & \\
\hline Single & -2.32 & 0,69 & 11.32 & 0.001 & 0.10 & & & & \\
\hline Married & -2.19 & 0.60 & 13.32 & $<0.001$ & 0.11 & & & & \\
\hline Divorced/separated & -0.64 & 0.64 & 1.01 & 0.315 & 0.53 & & & & \\
\hline ACE $1-10^{*}$ score & 0.39 & 0.07 & 33.07 & $<0.001$ & 1.49 & & & & \\
\hline
\end{tabular}

$B$ - unstandardized coefficient, SE - standard error, $Z$ - Wald test value, $p$ - level of statistical significance, Exp(B) - odds ratio, $\chi^{2}-\operatorname{chi}$ square test, ACE - adverse childhood experience. *Number of ACEs assessed with the ACE Study questionnaire.

\begin{tabular}{|c|c|c|c|c|c|c|c|c|c|}
\hline MODEL 2 & B & SE & $Z$ & $P$ & $\operatorname{Exp}(B)$ & Cox-Snell $R^{2}$ & Nagelkerke's $R^{2}$ & $\chi^{2}$ & $P$ \\
\hline Education level & & & 0.62 & 0.893 & & 0.082 & 0.178 & 56.19 & $<0.001$ \\
\hline Elementary & -1.05 & 1.47 & 0.51 & 0.476 & 0,35 & & & & \\
\hline Vocational & -0.24 & 1.12 & 0.05 & 0.827 & 0,78 & & & & \\
\hline Secondary & 0.05 & 0.29 & 0.03 & 0.866 & 1.05 & & & & \\
\hline Marital status & & & 29.24 & $<0.001$ & & & & & \\
\hline Single & -2.36 & 0.69 & 11.53 & 0.001 & 0.09 & & & & \\
\hline Married & -2.21 & 0.61 & 13.33 & $<0.001$ & 0.11 & & & & \\
\hline Divorced/separated & -0.71 & 0.65 & 1.21 & 0.272 & 0.49 & & & & \\
\hline ACE $1-13^{*}$ score & 0.35 & 0.06 & 31.12 & $<0.001$ & 1.42 & & & & \\
\hline
\end{tabular}

$B$ - unstandardized coefficient, SE - standard error, $Z$ - Wald test value, $p$ - level of statistical significance, Exp(B) - odds ratio, $\chi^{2}-$ chi square test, ACE - adverse childhood experience. *Number of ACEs assessed with the ACE (13) questionnaire.

\begin{tabular}{|c|c|c|c|c|c|c|c|c|c|}
\hline MODEL 3 & B & SE & $z$ & $P$ & $\operatorname{Exp}(B)$ & Cox-Snell $R^{2}$ & Nagelkerke's $R^{2}$ & $\chi^{2}$ & $P$ \\
\hline Education level & & & 0.35 & 0.950 & & 0.083 & 0.181 & 57.33 & $<0.001$ \\
\hline Elementary & -0.57 & 1.27 & 0.20 & 0.653 & 0.57 & & & & \\
\hline Vocational & -0.35 & 1.12 & 0.10 & 0.751 & 0.70 & & & & \\
\hline Secondary & 0.05 & 0.29 & 0.02 & 0.878 & 1.05 & & & & \\
\hline Marital status & & & 28.92 & $<0.001$ & & & & & \\
\hline Single & -2.29 & 0.69 & 10.94 & 0.001 & 0.10 & & & & \\
\hline Married & -2.13 & 0.61 & 12.26 & $<0.001$ & 0.12 & & & & \\
\hline Divorced/separated & -0.69 & 0.65 & 0.85 & 0.358 & 0.55 & & & & \\
\hline $\begin{array}{l}\text { ACE cumulative score on } \\
\text { ACE (13) questionnaire }\end{array}$ & 2.04 & 0.35 & 34.35 & $<0.001$ & 7.71 & & & & \\
\hline
\end{tabular}

$B$ - unstandardized coefficient, SE - standard error, $Z$ - Wald test value, $p$ - level of statistical significance, Exp (B) - odds ratio, $\chi^{2}-$ chi square test, $A C E$ - adverse childhood experience.

Seeking professional help from a psychologist/ psychotherapist and psychiatrist was reported by $36(6.4 \%)$ and 21 (3.7\%) of the 563 individu- als, respectively, who reported experiencing none of the four outcomes. These rates suggest that individuals were seeking help for other reasons 
Table IX. Association and correlation of selected characteristics with level of general self-efficacy assessed with Generalized Self-Efficacy Scale (GSES)

\begin{tabular}{|c|c|c|}
\hline \multirow[t]{2}{*}{ Parameter } & \multicolumn{2}{|c|}{ Generalized self-efficacy } \\
\hline & & $P$ \\
\hline Age at survey, M (SD) & $0.004^{*}$ & $0.923^{1}$ \\
\hline \multicolumn{3}{|l|}{ Sex } \\
\hline Female & $31.08(4.77)$ & $<0.001^{2}$ \\
\hline Male & $34.62(3.78)$ & \\
\hline \multicolumn{3}{|l|}{ Place of living } \\
\hline Village & $31.53(5.01)$ & \\
\hline $\begin{array}{l}\text { City of }<50,000 \\
\text { inhabitants }\end{array}$ & $31.26(4.57)$ & $0.296^{2}$ \\
\hline $\begin{array}{l}\text { City of } \geq 50,000 \\
\text { inhabitants }\end{array}$ & $31.79(4.79)$ & \\
\hline \multicolumn{3}{|l|}{ Educational level } \\
\hline Elementary & $30.43(3.87)$ & $0.037^{2}$ \\
\hline Vocational & $35.09(2.66)$ & \\
\hline Secondary & $31.55(5.08)$ & \\
\hline University degree & $31.54(4.55)$ & \\
\hline \multicolumn{3}{|l|}{ Occupational status } \\
\hline Employed & $31.49(4.80)$ & \\
\hline Unemployed & $35.00(3.25)$ & $0.001^{2}$ \\
\hline Student & $36.25(2.77)$ & \\
\hline \multicolumn{3}{|l|}{ Marital status } \\
\hline Single & $32.14(4.09)$ & \\
\hline Married & $31.33(4.86)$ & $0.246^{2}$ \\
\hline Divorced/separated & $32.11(5.57)$ & \\
\hline Widowed & $32.60(4.75)$ & \\
\hline \multicolumn{3}{|l|}{ Living status } \\
\hline Alone & $32.13(5.01)$ & \\
\hline With a family & $31.48(4.85)$ & $0.253^{2}$ \\
\hline With a partner & $32.33(3.89)$ & \\
\hline \multicolumn{3}{|l|}{ Having children } \\
\hline Yes & $31.47(4.82)$ & $0.102^{3}$ \\
\hline No & $32.08(4.75)$ & \\
\hline ACE $1-13^{4}$ score & $-0.139^{\star}$ & $<0.001^{1}$ \\
\hline \multicolumn{3}{|l|}{ Suicide attempt, M (SD) } \\
\hline Yes & $29.00(5.07)$ & \\
\hline No & $31.62(4.80)$ & $0.130^{3}$ \\
\hline \multicolumn{3}{|l|}{ Self-mutilation, M (SD) } \\
\hline Yes & $30.83(2.14)$ & $0.611^{3}$ \\
\hline No & $31.60(4.82)$ & \\
\hline
\end{tabular}

\begin{tabular}{|c|c|c|}
\hline \multirow[t]{2}{*}{ Parameter } & \multicolumn{2}{|c|}{ Generalized self-efficacy } \\
\hline & & $P$ \\
\hline \multicolumn{3}{|c|}{ Problem drinking, M (SD) } \\
\hline CAGE 0 & $31.64(4.85)$ & $0.418^{3}$ \\
\hline CAGE $\geq 1$ & $31.22(4.50)$ & \\
\hline \multicolumn{3}{|c|}{ Street drug use, M (SD) } \\
\hline Yes & $31.83(4.41)$ & $0.933^{3}$ \\
\hline No & $31.58(4.82)$ & \\
\hline \multicolumn{3}{|c|}{$\begin{array}{l}\text { Lifetime history of visiting a psychologist/ } \\
\text { psychotherapist, } M(S D)\end{array}$} \\
\hline Yes & $30.34(4.88)$ & $0.023^{3}$ \\
\hline No & $31.72(4.78)$ & \\
\hline \multicolumn{3}{|c|}{ Lifetime history of visiting a psychiatrist, M (SD) } \\
\hline Yes & $30.22(5.60)$ & $0.264^{3}$ \\
\hline No & $31.65(4.77)$ & \\
\hline
\end{tabular}

$P$ - level of statistical significance, $M-$ mean, SD - standard deviation. ${ }^{1}$ Spearman's rank correlation. ${ }^{2}$ Kruskal-Wallis $H$ test. ${ }^{3}$ Mann-Whitney U Test. ${ }^{4}$ Number of ACEs assessed with the ACE (13) questionnaire. *Spearman's rank correlation coefficient.

than the listed four outcomes. Being widowed as compared to single or married increased the likelihood of an individual visiting a psychiatrist (Table VIII B) or psychologist/psychotherapist during his/her lifetime (Table VII B). In general, loss of a relationship due to any reason is considered to be a risk factor for affective disorders, which could be a reason to consult a psychologist/psychotherapist or a psychiatrist [22].

We failed to confirm a relationship between ACES (as measured with the ACE Study questionnaire, ACE (13) questionnaire, and ACE (13) questionnaire score of $\geq 4$ vs. <4) and lifetime suicide attempt. In our study, a lifetime suicide attempt was reported by $1 \%$ of the study sample, which is lower than the figure from epidemiological data on reported suicidal behavior. Nock et al. (2008) found a lifetime prevalence of suicide attempt of $2.7 \%$ of a sample of 84,850 adults from the general population across 17 countries worldwide [23]. In our opinion, this discrepancy may be due to two potential reasons. First, a larger study group would qualify patients with a higher rate of mental disturbances and increase the number of self-reported suicide attempts. In the same study by Nock et al. (2008), individuals with mental disorders showed a higher lifetime prevalence of a suicide attempt and other suicidal behaviors (e.g., ideation, plan) than the general population (mood disorders, $\mathrm{OR}=3.4-5.9$; impulse-control disorders, $\mathrm{OR}=3.3-6.5$; anxiety disorders, $\mathrm{OR}=2.8-4.8$; substance use disorders, $O R=2.8-4.6$ ) [23]. Second, as 
Table X. Linear regression for variability in generalized self-efficacy assessed with GSES (Generalized Self-Efficacy Scale) in the whole study group and in males and females of the study group

\begin{tabular}{|c|c|c|c|c|c|c|c|c|c|}
\hline \multirow[t]{2}{*}{ Model } & \multicolumn{2}{|c|}{$\begin{array}{l}\text { Unstandardized } \\
\text { coefficients }\end{array}$} & \multirow{2}{*}{$\begin{array}{c}\begin{array}{c}\text { Standardized } \\
\text { coefficients }\end{array} \\
\text { Beta }\end{array}$} & \multirow[t]{2}{*}{$t$} & \multicolumn{3}{|c|}{$\begin{array}{l}95 \% \text { confidence interval } \\
\text { for B }\end{array}$} & \multirow[t]{2}{*}{$R^{2}$} & \multirow[t]{2}{*}{ Corr. $R^{2}$} \\
\hline & B & SE & & & LL & UL & $F$ & & \\
\hline Study group & 33.53 & 1.56 & - & $21.47^{* * *}$ & 30.47 & 36.60 & $11.48^{* * *}$ & 0.081 & 0.074 \\
\hline Sex & -3.41 & 0.52 & -0.25 & $-6.49^{\star * *}$ & -4.43 & -2.38 & & & \\
\hline Education & 0.16 & 0.31 & 0.02 & 0.50 & -0.46 & 0.77 & & & \\
\hline Employment & 0.79 & 1.16 & 0.03 & 0.68 & -1.48 & 3.07 & & & \\
\hline $\begin{array}{l}\text { Visit to } \\
\text { psychologist/ } \\
\text { psychotherapist }\end{array}$ & -0.61 & 0.64 & -0.04 & -0.95 & -1.87 & 0.66 & & & \\
\hline ACE $1-13^{1}$ score & -0.28 & 0.11 & -0.10 & $-2.50^{\star}$ & -0.49 & -0.06 & & & \\
\hline \multicolumn{10}{|l|}{ Males } \\
\hline \multicolumn{10}{|l|}{$\begin{array}{l}\text { Model not } \\
\text { significant }^{2}\end{array}$} \\
\hline Females & 27.39 & 4.89 & & $5.61^{\star \star \star}$ & 17.78 & 36.99 & & & \\
\hline Education & 0.19 & 0.36 & 0.02 & 0.55 & -0.50 & 0.89 & $2.39^{*}$ & 0.017 & 0.010 \\
\hline Employment & 3.42 & 4.76 & 0.03 & 0.72 & -5.93 & 12.77 & & & \\
\hline $\begin{array}{l}\text { Visit to } \\
\text { psychologist/ } \\
\text { psychotherapist }\end{array}$ & -0.63 & 0.68 & -0.04 & -0.94 & -1.97 & 0.69 & & & \\
\hline ACE $1-13^{1}$ score & -0.29 & 0.12 & -0.11 & $-2.47^{\star}$ & -0.53 & -0.06 & & & \\
\hline
\end{tabular}

shown in the study by Dube et al. (2001) [17], using the same study participants as the study by Nock et al. (2008) [23], participants exposed to childhood adversity reported a higher prevalence of a suicide attempt during childhood and adolescence than in adulthood. The data collected during the course of the study did not allow for assessment of the proximity of the analyzed outcome measures and exposure to ACEs. However, because of the cross-sectional nature of our study design, an assessment of the lifetime prevalence of outcome values rather than a retrospective report of temporal proximity is less confounded with recollection errors. Children who have experienced ACEs are more likely to attempt or complete suicide and to self-mutilate [24], which may be due to their dependence on adult household members while seeking professional help and a more limited capacity of young people to cope with stressors [25]. Indeed, research indicates that self-mutilation occurs in approximately $1 \%$ to $4 \%$ of adults in the United States [26, 27]. In our sample from the general Polish population, a positive lifetime history of self-mutilation was reported by $0.9 \%$, and an ACE (13) questionnaire score of at least 4 was associated with a 10.8-fold increase in lifetime self-mutilation (Table IV B).
In conclusion, adverse childhood experiences are highly prevalent in the general Polish population, as approximately half (48.1\%) of the individuals in this study reported exposure to at least one of the 13 assessed ACE categories. We found that the likelihood of lifetime street drug use, potential problem drinking, visiting a psychologist/psychotherapist, and visiting a psychiatrist increased as the number of ACEs (as measured on both the ACE Study questionnaire and the ACE (13) questionnaire) increased. An ACE (13) questionnaire score of $\geq 4$ was associated with a 10.8-fold increase in the likelihood of self-mutilation, a 3.26-fold increase in potential problem drinking, a 5.72-fold increase in visiting a psychologist/psychotherapist, and a 6.71-fold increase in likelihood of visiting a psychiatrist as compared to individuals reporting < 4 ACES. A remarkably strong association was found between severe childhood victimization ( $\geq 4$ vs. $<4$ of 13 self-confirmed ACE categories) and the likelihood of lifetime self-mutilation, potential problem drinking, visit to a psychologist/ psychotherapist, and visit to a psychiatrist.

Exposure to ACEs, as reported with the ACE (13) questionnaire, was found to explain significantly variability in generalized self-efficacy and 
the ability to cope with unpredicted and demanding stressors in adulthood. Thus, generalized self-efficacy may be an important target for secondary intervention after exposure to childhood adversity.

An additional important finding from this study - relevant for health policy - is that none of the individuals who reported a lifetime suicide attempt, self-mutilation, or street drug use also reported ever visiting a psychiatrist. Only a few of those individuals reported visiting a psychologist/psychotherapist ( 3 of 7,1 of 6 , and 3 of 18, respectively).

There were several limitations of our study. First of all, recall bias is possible when childhood victimization is self-reported. Data on final outcomes were self-reported, as no medical records were available. It is important to note that recall bias is always a possibility when self-reporting on a suicide attempt. There may be differences among adults who report a lifetime suicide attempt if, for example, the individual assesses that the attempt was serious or if the motivation was solely suicidal in the past.

Second, lifetime history of mental disorders was not documented in this study. Rather, we inquired about lifetime visits to a psychotherapist or psychiatrist. Thus, individuals who suffered from mental disorders but did not visit a professional may have not been accounted for in these outcome variables.

Overrepresentation of females in our study group may have limited interpretation of sex differences in prevalence of ACE categories.

Our study assessed lifetime prevalence of various outcome measures, and due to the cross-sectional design, our study did not provide data on time between the adversity (age $<18$ years) and each outcome.

\section{Acknowledgments}

We would like to thank Professor Vincent J. Felitti (Department of Preventive Medicine, Kaiser Permanente Medical Care Program; University of California, San Diego, CA, USA) for his encouragement and support during the study, as well as consultation regarding the first draft of the manuscript.

\section{Conflicts of interest}

The authors have declared no conflict of interest.

\section{References}

1. Felitti VJ, Anda RF, Nordenberg D, et al. Relationship of childhood abuse and household dysfunction to many of the leading causes of death in adults. The Adverse Childhood Experiences (ACE) Study. Am J Prev Med 1998; 14: 245-58.
2. Anda RF, Dong M, Brown DW, et al. The relationship of dverse childhood experiences to a history of premature death of family members. BMC Public Health 2009; 9: 106.

3. Bellis MA, Hughes K, Leckenby N, Hardcastle KA, Perkins $\mathrm{C}$, Lowey $\mathrm{H}$. Measuring mortality and the burden of adult disease associated with adverse childhood experiences in England: a national survey. J Public Health (Oxf) 2015; 37: 445-54.

4. Anda RF, Whitfield CL, Felitti VJ, et al. Adverse childhood experiences, alcoholic parents, and later risk of alcoholism and depression. Psychiatr Serv 2002; 53: 1001-9.

5. Jakubczyk A, Klimkiewicz A, Krasowska A, et al. History of sexual abuse and suicide attempts in alcohol-dependent patients. Child Abuse Negl 2014; 38: 1560-8.

6. Jaworska-Andryszewska P, Rybakowski J. Negative experiences in childhood and the development and course of bipolar disorder. Psychiatr Pol 2016; 50: 989-1000.

7. Berent D, Podgórski M, Kokoszka A. A need for intervention: childhood adversities are a significant determinant of health-harming behavior and poor self-efficacy in patients with alcohol dependence. An observational, cross-sectional study on the population of Central Poland. Adv Clin Exp Med 2018; 27: 1271-7.

8. Benight C, Bandura A. Social cognitive theory of posttraumatic recovery: the role of perceived self-efficacy. Behav Res Ther 2004; 42: 1129-48.

9. Shields AL, Caruso JC. A Reliability induction and reliability generalization study of the CAGE questionnaire. Educational and Psychological Measurement 2004; 64: 254-70.

10. Juczyński Z. Instruments for Measurement in Health Promotion and Health Psychology. $2^{\text {nd }}$ ed. Warsaw: Pracownia Testów Psychologicznych; 2012 [In Polish].

11. World Health Organization. The ICD-10 Classification of Mental and Behavioural Disorders: Clinical Description and Diagnostic Guidelines. Geneva: WHO; 1992.

12. Daeppen JB, Yersin B, Landry U, Pécoud A, Decrey H. Reliability and validity of the Alcohol Use Disorders Identification Test (AUDIT) imbedded within a general health risk screening questionnaire: results of a survey in 332 primary care patients. Alcohol Clin Exp Res 2000; 24: 659-65.

13. Berent D, Emilien G, Podgórski M, et al. SSTR4, Childhood adversity, self-efficacy and suicide risk in alcoholics. Transl Neurosci 2017; 8: 76-86.

14. World Health Organization. Global status report on alcohol and health 2018. Geneva: WHO; 2018. Available at: https:// apps.who.int/iris/bitstream/handle/10665/274603/ 9789241565639-eng.pdf (Accessed: 2.04.2019).

15. United Nations Office on Drugs and Crime. World Drug Report 2018. Austria: UNODC; 2018. Available at: https:// www.unodc.org/wdr2018/ (Accessed: 2.04.2019).

16. Zielińska-Danch W. The prevalence of waterpipe tobacco smoking among Polish youths. Arch Med Sci 2019. doi: 10.5114/aoms.2019.84487.

17. Dube SR, Anda RF, Felitti VJ, Chapman DP, Williamson DF, Giles WH. Childhood abuse, household dysfunction, and the risk of attempted suicide throughout the life span: findings from the Adverse Childhood Experiences Study. JAMA 2001; 286: 3089-96.

18. van Jzendoorn MH, Caspers K, Bakermans-Kranenburg MJ, Beach SRH, Philibert R. Methylation matters: interaction between methylation density and serotonin transporter genotype predicts unresolved loss or trauma. Biol Psychiatry 2010; 68: 405-7.

19. van Jzendoorn MH, Belsky J, Bakermans-Kranenburg MJ. Serotonin transporter genotype 5HTTLPR as a marker of 
differential susceptibility? A meta-analysis of child and adolescent gene-by-environment studies. Transl Psychiatry 2012; 2: e147.

20. Radziwiłtowicz W. Negative events in children's and adolescents lives - between the risk of depression and posttraumatic growth. Polskie Forum Psychologiczne 2018; 23: 543-56 [In Polish].

21. Radziwiłłowicz W. Depresja u dzieci i młodzieży. Analiza systemu rodzinnego - ujęcie kliniczne. Kraków: Oficyna Wydawnicza Impuls; 2010 [In Polish].

22. Jasik K, Jaślikowska U, Zbrojkiewicz $M$, et al. Factors related to occurrence of depressive disorders in adults. A systematic review of Polish literature in years 20092014. J Educ Health Sport 2016; 6: 297-318 [In Polish].

23. Nock MK, Borges G, Bromet EJ, et al. Cross-national prevalence and risk factors for suicidal ideation, plans and attempts. Br J Psychiatry 2008; 192: 98-105.

24. van der Kolk BA, Perry JC, Herman JL. Childhood origins of self-destructive behavior. Am J Psychiatry 1991; 148: 1665-71.

25. Brown J, Cohen P, Johnson JG, Smailes EM. Childhood abuse and neglect: specificity of effects on adolescent and young adult depression and suicidality. J Am Acad Child Adolesc Psychiatry 1999; 38: 1490-6.

26. Briere J, Gil E. Self-mutilation in clinical and general population samples: prevalence, correlates, and functions. Am J Orthopsychiatry 1998; 68: 609-20.

27. Klonsky ED, Oltmanns TF, Turkheimer E. Deliberate selfharm in a nonclinical population: prevalence and psychological correlates. Am J Psychiatry 2003; 160: 1501-8. 